\title{
MONTE CARLO METHODS AND APPLICATIONS
}

\section{MANAGING EDITOR}

Karl K. Sabelfeld, Novosibirsk

\section{EDITORIAL BOARD}

Kurt Binder, Mainz

Nicolas Bouleau, Paris

Alexandre J. Chorin, Berkeley

Ivan Dimov, Sofia

Alain Dubus, Brussels

Alexander D. Egorov, Minsk

Sergei M. Ermakov, St. Petersburg

John H. Halton, Chapel Hill

Stefan Heinrich, Kaiserslautern

Malvin H. Kalos, Livermore

Dominique Lepingle, Orléans

Yaohang Li, Tallahassee

Roman Makarov, Waterloo
Michael Mascagni, Tallahassee

Peter Mathé, Berlin

Harald Niederreiter, Linz

Shigeyoshi Ogawa, Kyoto

Giray Ökten, Tallahassee

Eckhard Platen, Sydney

Brian R. Sawford, Monash

Wolfgang C. Schmid, Salzburg

John Schoenmakers, Berlin

Nikolai A. Simonov, Novosibirsk

Ilya M. Sobol, Moscow

Jerry Spanier, Irvine

Denis Talay, Sophia Antipolis

Wolfgang Wagner, Berlin 
MONTE CARLO METHODS AND APPLICATIONS is a quarterly published journal presenting original articles on the theory and applications of Monte Carlo and quasi-Monte Carlo methods. Launched in 1995 the journal covers all stochastic numerics topics with emphasis on the theory of Monte Carlo methods and new applications in all branches of science and technology. The following topics will be covered: theory of Monte Carlo methods, quasi-Monte Carlo methods, integration, boundary value problems for PDE's, numerics of stochastic differential equations, simulation of random variables, stochastic processes and fields, and stochastic models in all fields of applied sciences.

All information regarding notes for contributors, subscriptions, Open access, back volumes and orders is available online at www.degruyter.com/mcma.

ABSTRACTED/INDEXED IN Baidu Scholar · Clarivate Analytics: Emerging Sources Citation Index; Web of Science · CNKI Scholar (China National Knowledge Infrastructure) · CNPIEC · DBLP Computer Science Bibliography · EBSCO (relevant databases) · EBSCO Discovery Service · EconBiz · Elsevier: SCOPUS · Gale/Cengage · Genamics JournalSeek · Google Scholar · J-Gate · JournalGuide · JournalTOCs · KESLI-NDSL (Korean National Discovery for Science Leaders) · Mathematical Reviews (MathSciNet) · Microsoft Academic $\cdot$ Naviga (Softweco) $\cdot$ Primo Central (ExLibris) ·

ProQuest (relevant databases) · Publons · ReadCube $\cdot$ Research Papers in Economics (RePEc) $\cdot$ SCImago (SJR) $\cdot$ Sherpa/RoMEO $\cdot$ Summon (Serials Solutions/ProQuest) · TDNet · TEMA Technik und Management · Ulrich's Periodicals Directory/ulrichsweb · WanFang Data · WorldCat (OCLC) ·

Zentralblatt Math (zbMATH).

ISSN 0929-9629 · e-ISSN 1569-3961 · CODEN MCMAC6

RESPONSIBLE EDITOR Karl K. Sabelfeld, Institute of Computational Mathematics and Mathematical Geophysics, Academy of Sciences, Siberian Branch, Lavrentjeva 6, 630090 Novosibirsk, Russia.

Email: karl@osmf.sscc.ru

JOURNAL MANAGER Antonia Laimina, De Gruyter, Genthiner Straße 13, 10785 Berlin, Germany.

Tel.: +49 (0)30 260 05-380, Fax: +49 (0)30 260 05-250

Email: antonia.laimina@degruyter.com

RESPONSIBLE FOR ADVERTISEMENTS Claudia Neumann, De Gruyter, Genthiner Straße 13, 10785 Berlin, Germany.

Tel.: +49 (0)30 260 05-226, Fax: +49 (0)30 260 05-264

Email: anzeigen@degruyter.com

(C) 2018 Walter de Gruyter GmbH, Berlin/Boston

TYPESETTING Dimler \& Albroscheit, Müncheberg

PRINTING Franz X. Stückle Druck und Verlag e.K., Ettenheim

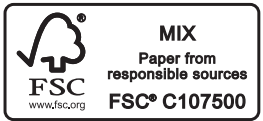




\section{Contents}

Xavier Warin

Nesting Monte Carlo for high-dimensional non-linear

PDEs - 225

Mohsine Benabdallah, Kamal Hiderah

Strong rate of convergence for the Euler-Maruyama approximation of one-dimensional stochastic differential equations involving the local time at point zero -249

Dmitriy Kolyukhin

Global sensitivity analysis for a stochastic flow problem -263

Debora Chan, Andrea Rey, Juliana Gambini, Alejandro C. Frery

Sampling from the $\mathcal{G}_{I}^{0}$ distribution -271
Toshihiro Yamada, Kenta Yamamoto

A second-order weak approximation of SDEs using a Markov chain without Lévy area simulation -289

Harold A. Lay, Zane Colgin, Viktor Reshniak, Abdul Q. M. Khaliq On the implementation of multilevel Monte Carlo simulation of the stochastic volatility and interest rate model using multi-GPU clusters - 309

Nikolai A. Simonov

Random walk algorithms for elliptic equations and boundary singularities -323 
